\title{
An Invitation from CQ to Join UNESCO in Expanding Bioethics
}

\section{Dear Bioethics Colleagues:}

Bioethics has grown to an international endeavor and bioethicists in developing countries need your help if they are to meet the ever increasingly complex challenges they face. UNESCO's project, "Assisting Bioethics Committees" (ABC) works to establish National Bioethics Committees in Member States and also assists them in developing their technical capacities.

One of the most pressing needs identified by the newly established National Bioethics Committees is to have access to pertinent literature, either printed or electronic. Toward this goal, UNESCO has developed a series of capacity building tools and is inviting public and private institutions around the world to collaborate by donating bioethics-related materials for this important purpose. Materials these nascent committees find especially helpful include: papers and reports on research ethics, environmental ethics, public policies and bioethics, organ donation and transplantation, traditional medicine, and informed consent as well as any other bioethics-related topics. The extra copies of such materials that donors are willing to transfer to the recipient Committee serve as vital tools for self-training and provide valuable resources for future references.

Individuals and organizations are welcome to make donations on an ad hoc basis as they become available, or by establishing an agreement with UNESCO stipulating a regular contribution. We prefer that the donated materials be sent to UNESCO (address below) where we will ensure they are distributed to the Committees that we work with. However, donated materials can be sent directly to the National Bioethics Committees, and we will be glad to provide you with all the necessary contact and mailing information. For any further details or questions, please do not hesitate to contact me.

Thank you for your consideration and I hope you will join us.

Dafna Feinholz

Chief of Bioethics Section of Social and Human Sciences

UNESCO

1 rue Miollis 75732 Paris CEDEX 15

France

Phone: : +33(0)1 45684994 .

E-mail: d.feinholz@unesco.org 